09.1

\title{
Достижение субпикосекундного временно́го разрешения при исследовании процессов анизотропной релаксации биологических молекул
}

\author{
() И.А. Горбунова, М.Э. Сасин, О.С. Васютинский \\ Физико-технический институт им. А.Ф. Иоффе РАН, Санкт-Петербург, Россия \\ E-mail: i.gorbunova@mail.ioffe.ru
}

Поступило в Редакцию 7 октября 2019г.

В окончательной редакции 25 октября 2019г.

Принято к публикации 1 ноября 2019г.

Разработан новый метод по схеме накачка-зондирование для исследования процессов анизотропной релаксации и переноса энергии в возбужденных состояниях многоатомных молекул при их возбуждении фемтосекундными лазерными импульсами. Метод применен для исследования процессов вращательной диффузии молекул NADH с временны́м разрешением около $0.6 \mathrm{ps}$. Впервые удалось зарегистрировать поглощение биологическими молекулами, находящимися в возбужденном состоянии, при накачке лазерными импульсами с энергией менее $1 \mathrm{~nJ}$.

Ключевые слова: метод накачка-зондирование, анизотропная релаксация, спектроскопия переходного поглощения, NADH.

DOI: $10.21883 /$ PJTF.2020.04.49041.18062

Спектроскопия переходного поглощения является мощным методом исследования быстрых фотоиндуцированных процессов, таких как перенос электронов и протонов, процессов изомеризации, а также исследования динамики возбужденных состояний. Особенно эффективной оказалась схема накачка-зондирование (pump-probe), при которой импульс накачки индуцирует фотопроцесс, а зондирующий импульс, задержанный относительно первого, контролирует изменение оптических свойств образца $[1,2]$.

Эта схема уже много лет применяется для изучения быстрых процессов в газовых и конденсированных средах [2-4]. Исследования быстрых процессов в биологических молекулах, возникающих при их возбуждении (релаксация возбужденных состояний, безызлучательная рекомбинация, вращательная диффузия, процессы переноса энергии), позволяют достигнуть ранее недоступного уровня понимания динамики внутри- и межмолекулярных взаимодействий [5-8].

Динамика возбужденных состояний многоатомных молекул, в том числе биологических, в значительной степени определяется быстрыми процессами анизотропной релаксации, которые успешно исследуются как с помощью наблюдения затухания поляризованной флуоресценции [9-11], так и методами накачка-зондирование с использованием различных комбинаций поляризации накачивающего и зондирующего пучков [4-6].

В настоящей работе сообщается о разработке и апробации нового метода по схеме накачка-зондирование для исследования процессов быстрой анизотропной релаксации и переноса энергии в возбужденных состояниях многоатомных молекул при их возбуждении фемтосекундными лазерными импульсами. Метод основан на высокочастотной модуляции поляризации накачивающего лазерного пучка с использованием фотоупругого модулятора с последующим выделением анизотропного вклада в регистрируемые сигналы с помощью высокочувствительной балансной схемы и дальнейшего синхронного детектирования. Метод был применен для исследования процессов вращательной диффузии восстановленной формы молекул NADH (никотинамид-аденин-динуклеотид) в водном растворе в субпикосекундном временно́м диапазоне. При этом было достигнуто временно́е разрешение 0.6 рs и продемонстрирована рекордная чувствительность, позволившая впервые зарегистрировать поглощение зондирующего лазерного излучения биологическими молекулами, возбужденными лазерными импульсами с энергией менее $1 \mathrm{~nJ}$.

Кофермент NADH является одной из наиболее важных биологических молекул, так как он принимает активное участие в протекании окислительно-восстановительных реакций в клетках живых организмов. Поскольку NADH обладает интенсивной флуоресценцией, он широко используется в качестве естественного флуоресцентного зонда для исследования биохимических процессов в живых клетках. Однако, несмотря на многочисленные исследования, процессы переноса энергии в возбужденных состояниях молекул NADH в настоящее время далеки от ясного понимания. В частности, это относится к анизотропной релаксации и переносу энергии между хромофорными группами аденина и никотинамида. Изучение динамики возбужденных состояний в молекулах NADH методом накачка-зондирование проводилось ранее в работах $[7,8]$, однако поляризационно-зависимых измерений и исследований анизотропной релаксации до сих пор не проводилось. 


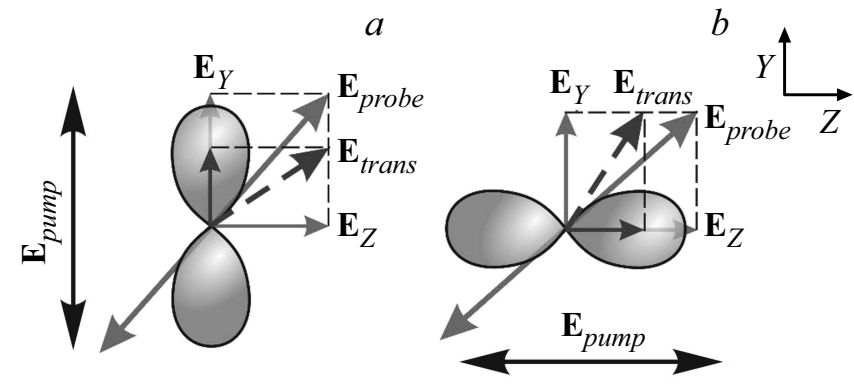

Рис. 1. Методика эксперимента. $\mathbf{E}_{\text {ритр }}$ - направление поляризации луча накачки, $\mathbf{E}_{\text {probe }}-$ направление поляризации пробного луча, $\mathbf{E}_{\text {trans }}$ - направление поляризации пробного луча, прошедшего через возбужденную среду. $a-$ поляризация излучения накачки направлена вдоль оси $Y$, оси возбужденных молекул выстроены вдоль оси $Y$ и компонента поляризации пробного пучка, направленная вдоль оси $Y$, поглощается больше, чем компонента поляризации пробного пучка, направленная вдоль оси $Z ; b-$ поляризация излучения накачки направлена вдоль оси $Z$, оси возбужденных молекул выстроены вдоль оси $Z$ и компонента поляризации пробного пучка, направленная вдоль оси $Z$, поглощается больше, чем компонента поляризации пробного пучка, направленная вдоль оси $Y$.

В исследованиях использовалась двухцветная схема накачка-зондирование, в которой лазерный импульс накачки возбуждал электронные переходы в молекулах $\mathrm{NADH}$ на длине волны $360 \mathrm{~nm}$, лежащей в полосе поглощения хромофорной группы никотинамида [12], а зондирующий лазерный пучок имел длину волны $720 \mathrm{~nm}$. Длительность импульсов накачки была около $100 \mathrm{fs}$, частота их повторения составляла $80 \mathrm{MHz}$, пробные импульсы имели те же характеристики, но были задержаны относительно импульсов накачки на регулируемый интервал времени $\Delta t$.

Геометрия эксперимента показана на рис. 1. Направление поляризации лазерного пучка накачки, распространявшегося вдоль оси $X$, периодически переключалось с вертикального (вдоль оси $Y$ ) на горизонтальное (вдоль оси Z) с частотой $100 \mathrm{kHz}$ при помощи фотоупругого модулятора. Зондирующий луч распространялся сонаправленно с возбуждающим лучом и был поляризован под углом $45^{\circ}$ к оси $Z$. Как показано на рис. $1, a$, при возбуждении молекул NADH светом, линейно поляризованным вдоль оси $Y$, возбуждались преимущественно те молекулы, оси которых были выстроены вдоль той же оси, и $Y$-компонента поляризации зондирующего луча поглощалась больше, чем $Z$-компонента. Аналогично при возбуждении молекул светом, поляризованным вдоль оси $Z$ (рис. $1, b$ ), преимущественно поглощалась $Z$-компонента поляризации зондирующего луча. В обоих случаях наблюдался поворот плоскости поляризации зондирующего луча, прошедшего через поглощающую кювету, который регистрировался с помощью балансной схемы детектирования.
Схема экспериментальной установки представлена на рис. 2.

Источником излучения служил перестраиваемый лазер Mai Tai (Spectra-Physics) с длительностью импульca $100 \mathrm{fs}$ и частотой повторения импульсов $80 \mathrm{MHz}$. Мощность излучения регулировалась аттенюатором 2. Часть излучения основной гармоники лазера с длиной волны $720 \mathrm{~nm}$ использовалась в канале зондирования, а часть удваивалась по частоте с помощью удвоителя 3 , и излучение второй гармоники с длиной волны $360 \mathrm{~nm}$ использовалось в канале накачки. Пучок накачки с энергией импульса около $1 \mathrm{~nJ}$ проходил через фотоупругий модулятор РEM-100 (Hinds Instruments) 13, контролируемый генератором частоты 23 , и через дихроичное зеркало 11 фокусировался линзой 12 в центр кюветы 10 с раствором. Исследовались водные растворы NADH с концентрацией 0.05-0.2 mM. Для предотвращения быстрого обесцвечивания при воздействии возбуждающего излучения осуществлялась прокачка раствора через кювету с использованием перистальтического насоса.

Зондирующий луч проходил через аттенюатор 4 и затем через линию задержки 6. Положение плоскости поляризации зондирующего луча контролировалось посредством волновой пластинки $\lambda / 2$ (7). Сфокусированный длиннофокусной линзой 9 зондирующий пучок проходил через кювету, отражался от дихроичного зеркала 11 и фокусировался обратно в центр кварцевой кюветы 10. Поскольку каустики зондирующего и накачивающего лучей совпадали только при втором проходе зондирующего луча через кювету, в эксперименте была фактически реализована схема сонаправленного распространения обоих лучей. Детальный ход пробного и накачивающего лучей через кювету представлен на вставке к рис. 2. Мощность зондирующего пучка на кювете составляла $40 \mathrm{~mW}$, а мощность пучка накачки $80 \mathrm{~mW}$.

Прошедший через кювету зондирующий луч направлялся в канал регистрации сигнала с помощью делителя 8 и зеркала 5 . Для предотвращения попадания прошедшего пучка накачки в канал регистрации использовалась система фильтрации 14 , состоящая из дихроичного зеркала и абсорбционного фильтра. Далее при помощи призмы Глана 15 осуществлялось разделение взаимно ортогональных поляризованных компонент зондирующего пучка, которые одновременно и независимо регистрировались фотодиодами 19 и 20. Сигналы с фотодиодов направлялись на входы дифференциального интегратора 21 с полосой пропускания $0-4 \mathrm{MHz}$, а полученный разностный сигнал, промодулированный по амплитуде на частоте $100 \mathrm{kHz}$, выделялся синхронным усилителем SR844 RF (Stanford Instruments) 22. Полученный сигнал был обусловлен линейным дихроизмом поглощения зондирующего луча в растворе, причем балансная схема детектирования позволила значительно уменьшить избыточные шумы, вызванные нестабильностью интенсивности излучения лазера и флуктуациями плотности раствора. При этом изменение времени задержки между 


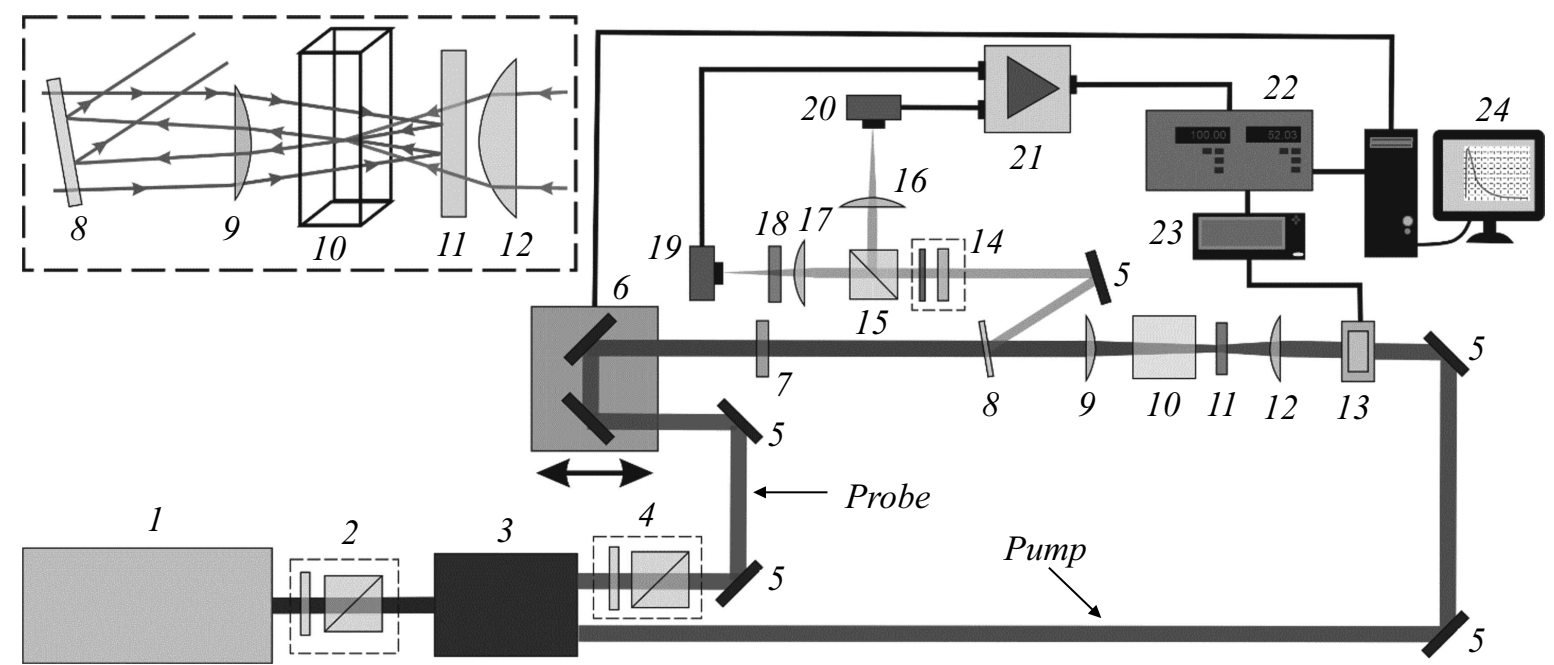

Рис. 2. Схема экспериментальной установки. 1 - лазер, $2,4-$ аттенюаторы, 3 - удвоитель частоты, 5 - поворотные зеркала, 6 - механическая линия задержки, 7 - полуволновая пластинка, 8 - светоделительная пластинка, 9, 12, 16, 17 - собирающие линзы, 10 - кварцевая кювета, 11 - дихроичное зеркало, 13 - фотоупругий модулятор, 14 - система фильтрации, $15-$ поляризационная призма, 18 - поляризатор, 19, 20 - кремниевые фотодиоды, 21 - дифференциальный интегратор, $22-$ синхронный усилитель, 23 - генератор частоты, 24 - ПК.

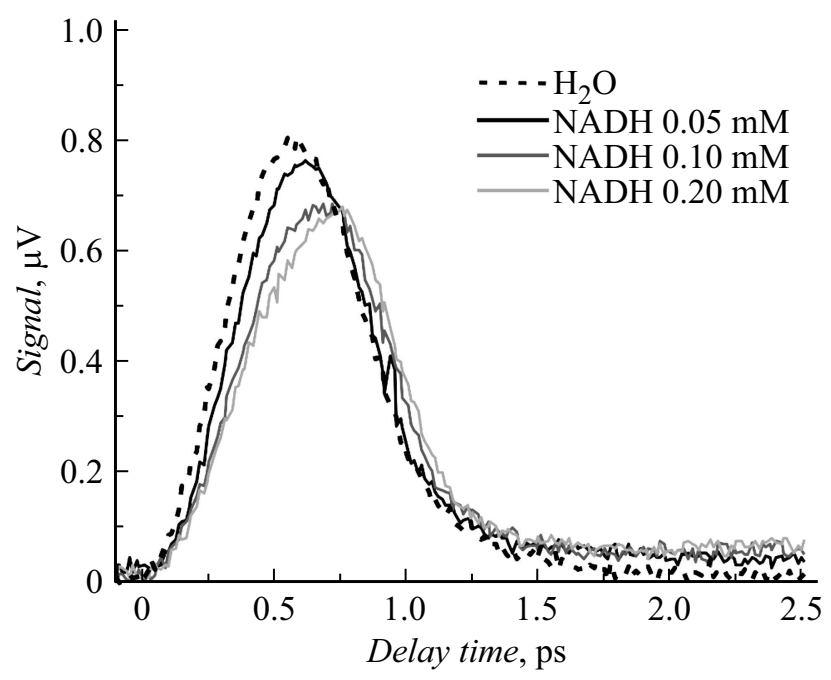

Рис. 3. Экспериментальные сигналы.

накачивающим и зондирующим импульсами позволяло зарегистрировать временну́ю зависимость анизотропной релаксации возбужденных молекул NADH.

На рис. 3 представлены полученные экспериментальные сигналы. Видно, что достигнутое временно́е разрешение составляет менее $0.6 \mathrm{ps}$ и обусловлено суммарной длительностью обоих лазерных импульсов и их дисперсией при прохождении поглощающей кюветы. Приведенные экспериментальные сигналы были получены для трех водных растворов $\mathrm{NADH}$ различной концентрации и для чистой воды. Как видно из рис. 3, для растворов $\mathrm{NADH}$ наблюдалось изменение формы линии сигнала по сравнению с сигналом чистой воды, сопровождающееся уменьшением амплитуды сигналов и сдвигом их максимума в сторону больших времен задержки при увеличении концентрации NADH.

Анализ полученных экспериментальных данных позволит исследовать времена анизотропной безызлучательной релаксации и времена вращательной диффузии в возбужденных состояниях молекул NADH, лежащие в пикосекундном и субпикосекундном диапазонах. Поскольку времена вращательной диффузии пропорциональны вязкости раствора, описанный в работе метод может быть использован для неинвазивного определения локальной внутриклеточной вязкости. Кроме того, так как измеряемые времена зависят от местоположения $\mathrm{NADH}$ внутри клетки, метод может быть применен для изучения роли этих коэнзимов в регулировании внутриклеточных окислительно-восстановительных реакций.

\section{Благодарности}

Авторы благодарят ФТИ им. А.Ф. Иоффе за предоставление оборудования для проведения экспериментов.

\section{Финансирование работы}

Работа выполнена при поддержке Российского фонда фундаментальных исследований (грант № 18-03-00038).

\section{Конфликт интересов}

Авторы заявляют, что у них нет конфликта интересов. 


\section{Список литературы}

[1] Henriksen N.E., Engel V. // Int. Rev. Phys. Chem. 2001. V. 20. P. 93-126.

[2] Berera R., van Grondelle R., Kennis J.T.M. // Photosynth. Res. 2009. V. 101. P. 105-118.

[3] Zhu J., Shcherbakova D.M., Hontani Y., Verkhusha V.V., Kennis J.T.M. // Sci. Rep. 2015. V. 5. P. 12840.

[4] Rumble C., Vauthey E. // Phys. Chem. Chem. Phys. 2019. V. 21. P. 11797-11809.

[5] Corrales M.E., Shternin P.S., Rubio-Lago L., de Nalda R., Vasyutinskii O.S., Banares L. // J. Phys. Chem. Lett. 2016. V. 7. P. $4458-4463$.

[6] Tros M., Woutersen S. // Opt. Lett. 2015. V. 40. P. 2607-2609.

[7] Heiner Z., Roland T., Léonard J., Haacke S., Groma G.I. // EPJ Web Conf. 2013. V. 41. P. 07003.

[8] Heiner Z., Roland T., Leonard J., Haacke S., Groma G.I. // J. Phys. Chem. B. 2017. V. 121. P. 8037-8045.

[9] Sasin M.E., Smolin A.G., Gericke K.-H., Tokunaga E., Vasyutinskii O.S. // Phys. Chem. Chem. Phys. 2018. V. 20. P. 19922-19931.

[10] Denicke S., Gericke K.-H., Smolin A.G., Shternin P.S., Vasyutinskii O.S. // J. Phys. Chem. A. 2010. V. 114. P. 96819692.

[11] Herbrich S., Al-Hadhuri T., Gericke K.-H., Shternin P.S., Smolin A.G., Vasyutinskii O.S. // J. Chem. Phys. 2015. V. 142. P. 024310.

[12] Сасин М.Э., Горбунова И.А., Безверхний Н.О., Бельтюков Я.M., Rubayo-Soneira J., Васютинский O.C. // Письма в ЖТФ. 2019. Т. 45. В. 13. С. 37-39. 